\title{
Multiple zooplankton species alter the stoichiometric interactions between producer and consumer levels
}

\author{
Christoph Plum ${ }^{1}$ (D) Helmut Hillebrand ${ }^{1,2,3}$
}

Received: 5 June 2019 / Accepted: 17 October 2019 / Published online: 11 November 2019

c) Springer-Verlag GmbH Germany, part of Springer Nature 2019

\begin{abstract}
Planktonic primary consumers have been shown to strongly influence phytoplankton communities via top-down effects such as grazing and nutrient recycling. However, it remains unclear how changes in consumer richness may alter the stoichiometric constrains between producer and consumer assemblages. Here we test whether the stoichiometry of producer-consumer interactions is affected by the species richness of the consumer community (multispecies consumer assemblage vs single consumer species). Therefore, we fed a phytoplankton assemblage consisting of two flagellates and two diatom species reared under a $2 \times 2$ factorial combination of light and nitrogen supply to three planktonic consumer species in mono- and polycultures. As expected, phytoplankton biomass and C:nutrient ratios significantly increased with light intensity while nitrogen limitation resulted in reduced phytoplankton biomass and increasing phytoplankton C:N but lower N:P. Differences in phytoplankton stoichiometry were partly transferred to the consumer level, i.e., consumer $\mathrm{C}: \mathrm{N}$ significantly increased with phytoplankton C:N. Consumer diversity significantly increased consumer biomass, resource use efficiency and nutrient uptake. In turn, consumer N:P ratios significantly decreased in consumer assemblages under high resource supply due to unequal changes in nutrient uptake. Consumer diversity further altered phytoplankton biomass, stoichiometry and species composition via increased consumption. Whether the effects of consumer diversity on phytoplankton and consumer performance were positive or negative strongly depended on the resource supply. In conclusion, the stoichiometric constraints of trophic interactions in multispecies assemblages cannot be predicted from monoculture traits alone, but consumer diversity effects are constrained by the resources supplied.
\end{abstract}

\section{Introduction}

Over the last decades, the biogeochemistry of marine ecosystems experienced an increased perturbation by anthropogenic activities. Fossil fuel burning, $\mathrm{N}_{2}$ fixation and the use of industrial fertilizers have constantly increased the

Responsible Editor: R. Bi.

Reviewed by C. Laspoumaderes and undisclosed experts.

Christoph Plum

c.plum@uni-oldenburg.de

1 University of Oldenburg, Institute for Chemistry and Biology of the Marine Environment (ICBM), Schleusenstr. 1, 26382 Wilhelmshaven, Germany

2 Helmholtz Institute for Functional Marine Biodiversity (HIFMB) at the University of Oldenburg, Oldenburg, Germany

3 Alfred Wegener Institute, Helmholtz-Centre for Polar and Marine Research [AWI], Bremerhaven, Germany global atmospheric input of carbon $(\mathrm{C})$, nitrogen $(\mathrm{N})$ and phosphorus $(\mathrm{P})$. The loads of additional $\mathrm{N}$, however, are disproportionally higher than $\mathrm{P}$, resulting in overall increasing $\mathrm{N}: \mathrm{P}$ ratios of the available resources (Elser et al. 2009; Vitousek et al. 2010; Peñuelas et al. 2012; Sardans et al. 2012). This is particularly the case in coastal areas where river runoffs discharge high concentrations of $\mathrm{N}$ into the ecosystem relative to P (Grizzetti et al. 2012; Burson et al. 2016). Such changes in N:P supply ratios can have major consequences for phytoplankton growth, community structure and elemental composition (Burson et al. 2016). Feeding rates, recycling rates, respiration, growth, and reproduction of consumer organisms, such as marine zooplankton, in turn are constrained by the balance of essential resources (C, N, P) in their food (Sterner and Elser 2002; Hessen et al. 2013; Elser et al. 2016).

Multiple studies in aquatic ecology have highlighted the vulnerability of stoichiometric constraints in trophic interactions to changes in resource availability, demonstrating that enhanced variability in phytoplankton nutrient 
content due to shifts in resource supply often results in altered consumers' growth, grazing rates and body elemental composition (Malzahn et al. 2007; Boersma et al. 2008; Peace et al. 2013; Elser et al. 2016). Changes in consumer performance can in turn influence primary producer biomass and stoichiometry via multiple feedback mechanisms, such as altered consumption rates, gross growth efficiency (Frost et al. 2006; Doi et al. 2010), and nutrient regeneration (Sterner 1990; Elser and Urabe 1999; Knoll et al. 2009).

The consequences of altered resource stoichiometry on interactions between different trophic levels are well understood for simple chain-like producer-consumer systems with single consumer species (Schoo et al. 2010; Malzahn et al. 2010; Malzahn and Boersma 2012; Meunier et al. 2012; Chen et al. 2017), but the question remains whether the observed nutritional constraints in trophic interactions differ when multiple species on the consumer and/or producer level are involved. Previous studies have demonstrated that experimental manipulations of species diversity at either consumer or producer level often affects the efficiency by which organisms capture resources, produce biomass and recycle essential nutrients, with the main focus on standing biomass (Hooper et al. 2005; Duffy et al. 2007; O'Connor et al. 2017). In addition, interactive effects of altered resource supply ratios and biodiversity have been addressed in experimental and theoretical studies on biodiversity and ecosystem functioning (Bruno et al. 2008; Cardinale et al. 2009; Gamfeldt and Hillebrand 2011; Hillebrand et al. 2014), focusing on realized productivity of producer species.

However, the consequences of altered resource stoichiometry for trophic interactions in the presence of multiple consumer species have rarely, if ever, been explicitly tested. So far, simultaneous effects of altered stoichiometry and consumer species richness have been analyzed mainly from a theoretical point of view (Hall et al. 2004; Loladze et al. 2004; Hall 2009; Elser et al. 2012). Based on multispecies assemblages, these studies concluded that different stoichiometric demands in consumer species may have strong implications for the coexistence of multiple consumers even under homogenous prey supply by occupying different stoichiometric niches.

Multispecies assemblages containing species with different stoichiometric demands may show intermediate stoichiometric signature compared to the specific elemental composition of the component species by averaging effects. Studies on freshwater zooplankton have shown that daphnid species differ in their P content and their stoichiometric flexibility (Hood and Sterner 2014). Consequently, the commonly proposed relative high $\mathrm{P}$ demand in daphnids compared to other consumer species may just represent the average stoichiometric signature of multiple daphnid species with different stoichiometric requirements.
Alternatively, the impact of multiple consumer species may differ from single species by non-averaging diversity effects. If consumer species differ in their nutritional demands and assimilation efficiencies, more consumer species may increase the overall extraction and regeneration of nutrients, thereby affecting producer stoichiometry. In fact, a mesocosm experiment conducted in marine rock pool communities demonstrated that consumer diversity can alter nutrient regeneration patterns, thereby decreasing phytoplankton $\mathrm{C}: \mathrm{N}$ ratios with increasing consumer species richness (Hillebrand et al. 2009).

Understanding the mechanisms underlying the relationship between species richness on different trophic levels and elemental stoichiometry in pelagic food webs is crucial to predict the potential consequences of anthropogenic-induced changes in marine biogeochemistry and biodiversity. Here, we test the idea that planktonic consumer species with different stoichiometric demands may alter the efficiency of resource use in multispecies assemblages with consequences for consumer individual biomass, consumer body stoichiometry and feedbacks on phytoplankton biomass and elemental composition. To test this prediction, we performed a laboratory experiment manipulating resource supply in a $2 \times 2$ factorial manipulation of $\mathrm{N}$ and light. On primary producer level we used a four-species phytoplankton assemblage consisting of the flagellates Rhodomonas salina and Tetraselmis sp. as well as the diatom species Chaetoceros danicus and Skeletonema costatum. Three taxonomically different consumer species with specific stoichiometric demands were used and included juveniles of the brine shrimp Artemia salina, copepodites of the marine copepod Acartia tonsa and the brackish rotifer Brachionus plicatilis. We contrasted single consumer treatments (consumer monocultures) to multispecies assemblages (consumer polycultures) and a grazer-free control. We measured phytoplankton biovolume and consumer individual biomass as well as the elemental composition of producers and consumers to test the following rationale:

Before grazing, phytoplankton biomass and elemental ratios will reflect the resource supply ratios. An increase in light and $\mathrm{N}$ availability is expected to increase phytoplankton biomass while phytoplankton $\mathrm{C}: \mathrm{N}$ and $\mathrm{C}: \mathrm{P}$ ratios are expected to increase with light but $\mathrm{N}: \mathrm{P}$ and $\mathrm{C}: \mathrm{N}$ should decrease with high $\mathrm{N}$ supply. The effects of light and $\mathrm{N}$ on phytoplankton biomass and elemental ratios will be transferred to the next trophic level such that consumer individual biomass and resource use efficiency will increase with relatively low phytoplankton C:N and C:P ratios. Based on the assumption that homeostatic regulation in metazoan zooplankton is often not entirely strict, we further expect that consumer elemental ratios increase with phytoplankton elemental ratios (H1). The effect of phytoplankton stoichiometry on consumer performance (biomass production, 
resource use efficiency, stoichiometry) will significantly differ between consumer monocultures and polycultures by either averaging or non-averaging effects $(\mathrm{H} 2)$.

During the grazing period, biomass and elemental ratios $(\mathrm{C}: \mathrm{N}, \mathrm{C}: \mathrm{P}, \mathrm{N}: \mathrm{P})$ of phytoplankton grazed by consumer polycultures will differ from expectations based on phytoplankton performance in consumer monocultures. Consumer polycultures will alter the overall efficiency of resource assimilation and nutrient regeneration, resulting in lower phytoplankton biomass and shifts in phytoplankton elemental ratios in consumer polycultures compared to expectations based on consumer monoculture treatments (H3).

\section{Materials and methods}

\section{Pre-experimental conditions}

The phytoplankton cultures used in the experiment originated from culture collections at the ICBM and were isolated and identified according to Kraberg et al. (2010). Prior to the experiment, stock cultures of the flagellates Rhodomonas salina and Tetraselmis sp. as well as the diatom species $S$. costatum and $C$. danicus were cultured under constant temperature $\left(18{ }^{\circ} \mathrm{C}\right)$ and light conditions in $f / 2$ full medium (Guillard and Ryther 1962) until they reached an optimal density to inoculate the experimental cultures.

Pre-filtered seawater $(0.2 \mu \mathrm{m})$ was used to produce the experimental medium. For the $\mathrm{N}$-enriched medium $(\mathrm{N}+)$, $\mathrm{N}$ was added to a final concentration of $1083 \mu \mathrm{mol} \mathrm{N} \mathrm{L}{ }^{-1}$ while the limited medium $(\mathrm{N}-$ ) had a final concentration of $54 \mu \mathrm{mol} \mathrm{N} \mathrm{L}{ }^{-1}$. All other nutrients $(\mathrm{P}, \mathrm{Si}, \mathrm{Fe})$ were added according to the $f / 2$ medium prescription (Guillard and Ryther 1962).

The consumer species A. tonsa (Copepoda, Calanoida), A. salina (Branchiopoda, Anostraca), and B. plicatilis (Monogononta, Ploima) were tested in pre-experiments to ensure that they graze and grow on the selected phytoplankton species. Although these particular consumer species do not coexist in natural systems, they were chosen because they represent important herbivores in their specific environment, cover different consumer classes and show different stoichiometric demands.

Acartia tonsa eggs, obtained from the 'Biologische Anstalt Helgoland' (Alfred Wegener Institute), were hatched at $18{ }^{\circ} \mathrm{C}$ in $12: 12$-h dark:light cycle in $0.2-\mu \mathrm{m}$-filtered seawater. Nauplii of A. tonsa were collected between 24 and $48 \mathrm{~h}$ after hatching to ensure a similar developmental stage of the cohort and were daily fed with $R$. salina until copepodite stage CIII before they were used for the experiment.

Resting eggs of the brine shrimp A. salina, also obtained from the 'Biologische Anstalt Helgoland' (Alfred Wegener Institute), were hatched 4 days prior to the experiment under the same conditions as A.tonsa. Larvae were separated from unhatched eggs and reared under the same conditions as A. tonsa. We used juvenile $A$. salina for the experiment to keep the size difference between consumer species as small as possible.

Stock cultures of the rotifer $B$. plicatilis were obtained from the Institute for Biology und Environmental Science (University of Oldenburg) and cultured continuously in Petri dishes under the same constant light and temperature conditions as the other species. The cultures were fed and refreshed once per week by transferring about 50 egg-carrying females into new Petri dishes filled with Rhodomonas culture. Two weeks prior to the experiments, synchronized individuals were transferred into $1 \mathrm{~L}$ of Rhodomonas culture to reach a sufficient amount of individuals for the experiment.

Using juvenile stages of $A$. tonsa and A. salina, and establishing a 4-day grazing phase (shorter than the generation time of B. plicatilis) in the experiment, reproduction of zooplankton organisms was prevented to avoid biasing results due to density effects or reproduction investment. Before the consumer species were finally added to the corresponding experimental treatments, copepods, brine shrimps, and rotifers were gently rinsed over a $200 \mu \mathrm{m}$ and $50 \mu \mathrm{m}$ sieve, respectively, to ensure similar intraspecific size and to separate the organisms from food particles and feces.

Although the use of such different consumer species resulted in highly artificial consumer assemblages, it allowed us to assess the mechanisms behind our main question whether the stoichiometric interaction between producer and consumer species differ when multiple instead of single consumer species are present.

\section{General experimental setup}

The experiment was conducted in laboratory microcosms (1000-mL Schott flasks) under batch culture conditions and at a constant temperature of $18{ }^{\circ} \mathrm{C}$. Phytoplankton assemblages containing Rhodomonas salina, Tetraselmis sp. S. costatum and $C$. danicus were reared under different light:N regimes $(2 \times 2$ factorial combination of light and $\mathrm{N}$, see below) with five consumer treatments (three single consumer species, a mixture consisting of all three species, and a consumer-free control). Each combination of light, $\mathrm{N}$, and consumer treatment was run in triplicates. To ensure an equal biovolume at the beginning of the experiment, abundance (cells $\mathrm{mL}^{-1}$ ) and biovolume $\left(\mu \mathrm{m}^{3}\right)$ of the stock cultures were determined prior to the experiment (see below). The experimental cultures were inoculated with a final biovolume of $113,600 \mu \mathrm{m}^{3} \mathrm{~mL}^{-1}$ corresponding to a phytoplankton cell density of 450 cells $\mathrm{mL}^{-1}$. The $\mathrm{N}+$ and $\mathrm{N}-$ phytoplankton cultures were exposed to high-light (HL, $100 \mu \mathrm{mol} \mathrm{m}^{-2} \mathrm{~s}^{-1}$ ) and low-light conditions (LL, $30 \mu \mathrm{mol} \mathrm{m}^{-2} \mathrm{~s}^{-1}$ ). 
During the experiment, the phytoplankton cultures were gently aerated to avoid stratification in the bottle. Before adding the zooplankton species, phytoplankton cultures were reared for 10 days with a 12:12-h light:dark cycle to allow biomass buildup and to ensure a sufficient limitation under $\mathrm{N}$ and light deficiency.

After this growing phase, a constant volume of each replicate was sampled and analyzed for biomass and C:N:P content of the algae. Afterwards, the consumer species were added to the phytoplankton cultures as single species (monocultures) and in multispecies assemblages (polycultures), respectively. Consumer monocultures were inoculated with 2000 individuals of $B$. plicatilis, 400 individuals of $A$. tonsa and 300 individuals of $A$. salina. The polycultures were inoculated in an additive design (Snaydon 1991). Although these abundances are still high compared to natural conditions, they provided a sufficient number of individuals needed for the later chemical analyses.

After another 4 days, both consumer and phytoplankton were sampled and measured for biomass and $\mathrm{C}: \mathrm{N}: \mathrm{P}$ content. Additional samples were taken to analyze the remaining dissolved $\mathrm{N}$ and $\mathrm{P}$ contents of the medium.

Although the chosen additive design may confound consumer density and diversity, it can reflect real situations when species lost from a consumer assemblage are not numerically compensated for (Cardinale et al. 2003). This is the case when-like in our experiment - the time frame is too short for numerical responses to the local extinction of single species. To account for the higher animal densities in the consumer polycultures, we compared expectations from the summed performance of all three consumer monocultures to the observed performance of the consumer polycultures (for details see "Statistical analyses"). This allowed us to determine whether consumer diversity had an effect exceeding that expected from enhanced consumer abundance in multispecies assemblages. By keeping consumer densities as low as possible, we additionally accounted for potential nonlinear functional responses which would restrict the conclusions to consumer density effects (Sih et al. 1998). Based on the outcome of pre-experiments, we additionally assured that the sampling was conducted during the exponential phase of the functional responses, thereby avoiding consumer density-dependent effects. A further benefit of the additive series design is that intra- and interspecific interactions are less likely to be confounded-a problem that can hinder interpretation of treatment effects in the replacementseries design where the density of each species is inversely proportional to richness (Snaydon 1991; Jolliffe 2000).

\section{Analytical procedures}

At two sampling days (before and after grazing), samples from each replicate were taken for the analyses of phytoplankton biovolume $\left(\mu \mathrm{m}^{3} \mathrm{~mL}^{-1}\right)$ as well as particulate C, N, and P content. Samples for analysis of cell densities and species abundance were preserved in Lugol with $1 \%$ final concentration and counted with an inverted microscope.

To convert phytoplankton cell numbers into biovolume, the specific cell volume was calculated by approximation to a defined geometric shape (Hillebrand et al. 1999). Final phytoplankton biovolume was calculated by multiplying single cell volume with corresponding cell counts.

For nutrient samples, a volume of 20-200 mL was filtered on pre-combusted Whatman GF/F filters. The filtered volume depended on the phytoplankton cell density of the different treatments. To ensure an equal biovolume in each replicate after sampling, additional volume was removed if necessary. Prior to measurements, the $\mathrm{C} / \mathrm{N}$ and $\mathrm{P}$ filters were dried for at least $48 \mathrm{~h}$ at $60{ }^{\circ} \mathrm{C}$ and stored there until analysis. To obtain samples for dissolved nutrients, $20 \mathrm{~mL}$ of the filtered phytoplankton suspension were retained in PE bottles and stored at $-20{ }^{\circ} \mathrm{C}$ until analysis.

Consumer biomass was determined as carbon content per individual ( $\mu \mathrm{g} \mathrm{C}$ ind. $^{-1}$ ). To obtain samples for consumer $\mathrm{C}, \mathrm{N}$ and $\mathrm{P}$ content, individuals of $A$. tonsa, A. salina, and $B$. plicatilis were first separated from primary producers and feces by rinsing them over $200-\mu \mathrm{m}$ and $50-\mu \mathrm{m}$ meshes. About 20-30 individuals of each species from each culture were then isolated, filtered on pre-combusted Whatman $\mathrm{GF} / \mathrm{F}$ filters, and dried at $60{ }^{\circ} \mathrm{C}$ for later analysis. The remaining individuals were preserved with Lugol and counted afterwards to determine total abundance. The $\mathrm{C} / \mathrm{N}$ elemental composition of phytoplankton and consumer species was measured using a CHN analyzer (Thermo, Flash EA 1112). Particulate phosphate was measured photometrically as orthophosphate by molybdate reaction after sulfuric acid and heat digestion modified after Grasshoff et al. (1999).

\section{Statistical analyses}

Before the consumer species were added to the phytoplankton cultures, the effect of light and $\mathrm{N}$ supply on phytoplankton $\mathrm{C}: \mathrm{N}: \mathrm{P}$ molar ratios and biomass $\left(\mu \mathrm{mol} \mathrm{C} \mathrm{L}^{-1}\right)$ was analyzed by a two-way ANOVA with $\mathrm{N}$ and light as independent factors. To exclude systematic differences in phytoplankton response, variables between the grazer treatments before the grazers were actually added; we conducted an additional one-way ANOVA with species as independent factor for phytoplankton biomass and elemental ratios before grazing.

We additionally performed planned ANOVA contrasts on the change in phytoplankton response variables over the grazing period, expressed as $\Delta$ values, between the consumer free control treatments and consumer presence ( 0 vs. 1). This served as a test of the a priori-defined hypothesis that grazer presence will alter phytoplankton biomass and elemental ratios. The use of $\Delta$ values additionally allowed 
for compensation of random variation in starting conditions between replicates before the consumer species were added to the phytoplankton cultures.

Consumer individual biomass ( $\mu \mathrm{g} \mathrm{C}$ ind. ${ }^{-1}$ ), elemental molar ratios, resource use efficiency (called RUE hereafter) and $\mathrm{N}$ uptake efficiency (NUE) were analyzed by a threeway ANOVA at the end of the experiment using N, light, and consumer treatments as independent factors to test for $\mathrm{H} 1$. The effect of light and $\mathrm{N}$ on consumer $\mathrm{C}: \mathrm{P}$ and $\mathrm{N}: \mathrm{P}$ was exceptionally tested with a two-way analysis since there were too many $p$ values missing for a three-way ANOVA. The calculation of the consumer RUE was adapted from Ptacnik et al. (2008), where phytoplankton RUE is defined as the ratio between phytoplankton biomass (as chlorophyll $a$ and carbon content) and total phosphorus (TP) as the limiting resource. We thus expressed consumer RUE by the ratio between the consumer species-specific total amount of

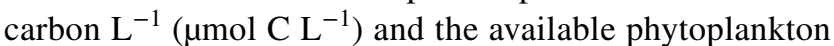
$\mathrm{N}\left(\mu \mathrm{mol} \mathrm{N} \mathrm{L}{ }^{-1}\right)$ as the limiting resource $\left(\mu \mathrm{mol} \mathrm{C} \mathrm{zoo}_{\mathrm{zo}} / \mu \mathrm{mol}\right.$ $\mathrm{N}_{\text {phyto }}$ ). Accordingly, the consumer NUE was calculated as species-specific consumer $\mathrm{N} \mathrm{L}^{-1}\left(\mu \mathrm{mol} \mathrm{N} \mathrm{L} \mathrm{L}^{-1}\right)$ per unit

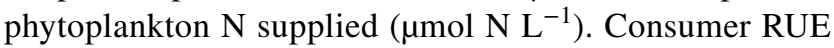
and NUE, respectively, were determined after the grazing period of 4 days. Significant differences between group levels reported in the results were detected by Tukey's honest significant difference test (HSD, $p<0.05$ ).

In case of significant interactions between resource supply (in terms of light and $\mathrm{N}$ ) and consumer elemental composition, we additionally tested for significant speciesspecific differences between the resource supply treatments using an independent $t$ test for each single species. Furthermore, we used Spearman rank correlation to test whether phytoplankton elemental ratios were correlated with consumer elemental ratios and biomass (H1).

To test whether consumer species richness influenced the phytoplankton and consumer response variables in a way that deviated from expected additive effects $(\mathrm{H} 2$ and $\mathrm{H} 3)$, the net diversity effect (NDE) was calculated as the difference between observed values in polycultures and the expected values based on monoculture performance (Loreau and Hector 2001). Diversity effects on absolute values should sum up, whereas effects on relative values should average. Thus, expected yields (consumer biomass) in consumer polycultures correspond to the sum of monoculture performance $(A+B+C)$. For ratios $(\mathrm{C}: \mathrm{N}, \mathrm{C}: \mathrm{P}, \mathrm{N}: \mathrm{P}, \mathrm{RUE}, \mathrm{NUE})$ which were changed in monocultures to $a$ by species $\mathrm{A}, b$ by species $\mathrm{B}$, and $c$ by species $\mathrm{C}$, the combination of $\mathrm{A}, \mathrm{B}$, and $\mathrm{C}$ is expected to result in $0.33 \times(a+b+c)$. The sum of monoculture performance was based on randomized attribution of the replicate parallels. Significant deviation of NDE from 0 indicates that the observed performance in polycultures differed from additive predictions, which was tested with $t$ tests on square-root-transformed NDE values. Positive NDE values indicate an increase of the corresponding response variable in polycultures relative to the expectation from monocultures, while negative values indicate a relative decrease in polycultures.

\section{Results}

\section{Phytoplankton response to resource supply before grazing}

As expected, elevated light intensity (HL) significantly increased phytoplankton biovolume and cellular C:nutrient ratios, while reduced $\mathrm{N}$ availability resulted in decreasing phytoplankton biovolume and lower phytoplankton C:P and $\mathrm{N}: \mathrm{P}$ ratios as well as increased $\mathrm{C}: \mathrm{N}$ ratios, indicating enhanced phosphate uptake and reduced $\mathrm{N}$ uptake under $\mathrm{N}$ depletion (see Appendix Figs. 5, 6; Table 4). The significant interaction term light $\times \mathrm{N}$ (Appendix Fig. 5; Table 4) revealed that the effect of $\mathrm{N}$ addition on phytoplankton biomass and elemental ratios was more pronounced under HL conditions (Appendix Figs. 5, 6; Table 4).

The resource use efficiency (RUE) and $\mathrm{N}$ uptake efficiency (NUE) were significantly higher under reduced $\mathrm{N}$ supply while light had no significant impact on RUE and NUE. However, the significant interaction light $\times \mathrm{N}$ revealed that the effect of $\mathrm{N}$ was restricted to the HL treatments with RUE and NUE being highest under $\mathrm{HL}$ and $\mathrm{N}-$ and lowest under HL N+ (Appendix Fig. 5; Table 4).

Additionally, the relative abundance of phytoplankton species significantly differed between the factorial combinations of light and $\mathrm{N}$ supply (see Appendix Fig. 7).

\section{Consumer performance (H1 and H2)}

Overall, consumer individual biomass significantly increased with elevated light [ANOVA, $F(1,47)=87.492, p<0.001$ ] and $\mathrm{N}$ supply [ANOVA, $F(1,47)=51.097, p<0.001$ ], with synergistic effects of both resources [ANOVA, significant interaction light $\times \mathrm{N}, F(1,47)=15.922, p<0.001]$. When additionally accounting for species identity [ANOVA, interaction term light $\times \mathrm{N} \times$ species, $F(1,47)=10.927$, $p<0.001]$, the overall response of consumer biomass was consistent in its direction but the magnitude was species specific for the light and $\mathrm{N}$ manipulations (Fig. 1a).

Under HL N+conditions, the significant positive NDE indicated that consumer biomass was higher in multispecies assemblages than expected from monoculture performance. Under LL N- in turn, consumer polycultures decreased consumer biomass compared to monocultures, indicated by the significantly negative NDE (Fig. 1b; Table 1).

Consumer RUE was significantly higher under N[ANOVA, $F(1,47)=116.19, p<0.001$ ], and low-light 
Fig. 1 Left panel shows a consumer biomass, $\mathbf{c}$ RUE and $\mathbf{e}$ NUE of the different consumer species in monocultures (A, $\mathrm{B}$ and $\mathrm{C}$ on the $x$-axis) and polycultures (MIX A, MIX B and MIX C) under different factorial combinations of light and nitrogen availability. Data are mean values with standard error (mean \pm SE). The right panels $\mathbf{b}, \mathbf{d}, \mathbf{f}$ show the NDE for the respective response variables. Values for the NDE are squareroot transformed. A, Artemia salina; $\mathrm{B}$, Brachionus plicatilis; C, Copepod Acartia tonsa; MIX A, B, C= corresponding individual consumer species in polyculture
Table $1 t$ test results for the NDEs on consumer response variables
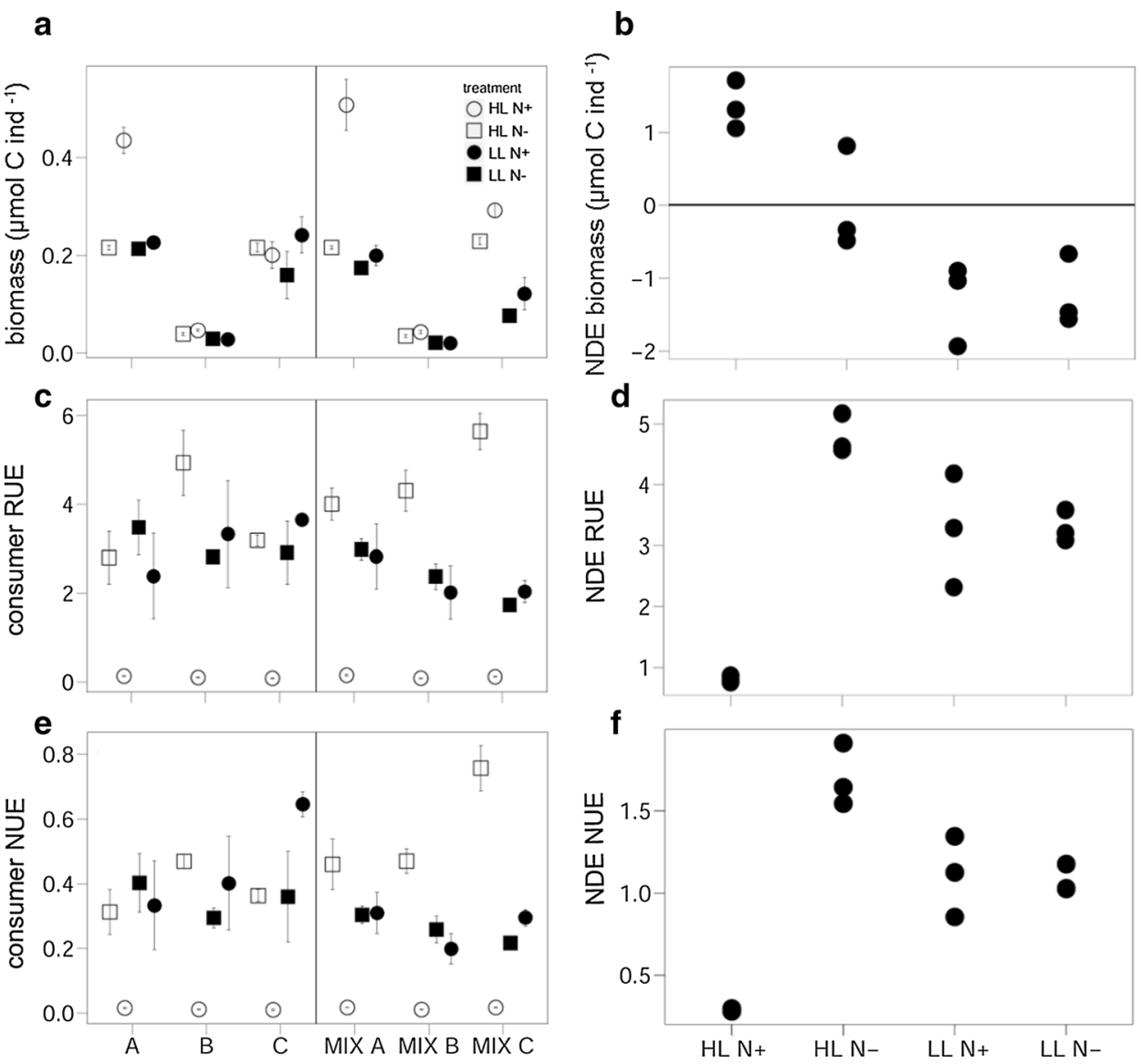

\begin{tabular}{|c|c|c|c|c|c|c|c|c|}
\hline \multirow[t]{2}{*}{ Response } & \multicolumn{2}{|l|}{$\mathrm{HL} \mathrm{N+}$} & \multicolumn{2}{|l|}{ HL N- } & \multicolumn{2}{|l|}{ LL N+ } & \multicolumn{2}{|l|}{ LL N- } \\
\hline & $t$ value & $p$ & $t$ value & $p$ & $t$ value & $p$ & $t$ value & $p$ \\
\hline Consumer biomass & 7.145 & $<0.05$ & 0.002 & 0.997 & -3.964 & 0.058 & -4.326 & $<0.05$ \\
\hline Consumer RUE & 26.477 & $<0.01$ & 25.100 & $<0.01$ & 6.078 & $<0.05$ & 21.901 & $<0.05$ \\
\hline Consumer NUE & 59.543 & $<0.001$ & 15.486 & $<0.01$ & 7.8146 & $<0.05$ & 21.750 & $<0.01$ \\
\hline Consumer C:N & -2.119 & 0.168 & -1.020 & 0.414 & 3.782 & 0.063 & -0.025 & 0.982 \\
\hline Consumer C:P & -2.975 & 0.096 & 0.026 & 0.981 & 0.131 & 0.907 & 0.835 & 0.491 \\
\hline Consumer N:P & -4.266 & 0.050 & 0.422 & 0.713 & -0.075 & 0.946 & 0.647 & 0.584 \\
\hline
\end{tabular}

Significant values of the $t$ test are shown in bold, marginal significant values in italic only. For abbreviations, see Table 1

conditions [ANOVA, $F(1,47)=9.7104, p<0.01$ ]. However, the significant interaction term light $\times \mathrm{N}$ revealed that the effect of $\mathrm{N}$ was mainly restricted to high-light conditions [ANOVA, light $\times \mathrm{N}, F(1,47)=114.94, p<0.001$ ] This outcome was still observed when including species identity [ANOVA, interaction term light $\times \mathrm{N} \times$ species, $F(5,47)=2.6525, p<0.05]$. Consumer NUE showed the same response to light and $\mathrm{N}$ conditions as observed for consumer RUE (Fig. 1c, e). Consumer RUE and NUE significantly increased in consumer polycultures when compared to the expected values based on the monoculture performance (NDE, Fig. 1d, f; Table 1).

Overall, consumer $\mathrm{C}: \mathrm{N}$ ratios were significantly higher when exposed to N-reduced phytoplankton cultures [threeway ANOVA, $F(1,46)=12.748, p<0.001$ ], while consumer $\mathrm{C}: \mathrm{P}$ and $\mathrm{N}: \mathrm{P}$ were not altered significantly by the influence of N. Light, in turn, had no significant effect on consumer $\mathrm{C}: \mathrm{N}$, but significantly decreased consumer $\mathrm{C}: \mathrm{P}$ and $\mathrm{N}: \mathrm{P}$ [C:P, two-way ANOVA, $F(1,57)=12.467, p<0.001 ; \mathrm{N}: \mathrm{P}$, two-way ANOVA, $F(1,57)=8.3467, p<0.01]$. Although the 
intensity of the light and $\mathrm{N}$ effects on consumer body stoichiometry was species specific (Fig. 2a, c, e), there was no significant interaction between light, $\mathrm{N}$ and species identity.

In addition to the ANOVA, the Spearman rank correlation between consumer $\mathrm{C}: \mathrm{N}$ and phytoplankton $\mathrm{C}: \mathrm{N}$ revealed that consumer $\mathrm{C}: \mathrm{N}$ significantly increased with phytoplankton $\mathrm{C}: \mathrm{N}(r s=0.58, N=46, p<0.001)$, while the correlation between consumer C:P and phytoplankton C:P $(r s=0.22$, $N=45, p=0.15)$ as well as consumer $\mathrm{N}: \mathrm{P}$ and phytoplankton $\mathrm{N}: \mathrm{P}(r s=0.069, N=45, p=0.65)$ was non-significant.

Only consumer $\mathrm{N}: \mathrm{P}$ molar ratios were significantly affected by consumer polycultures with a negative NDE under HL $\mathrm{N}+$ indicating that consumer $\mathrm{N}: \mathrm{P}$ was lower in polycultures than expected from monoculture performance (Fig. 2f; Table 1). The other elemental ratios were not altered when more than one consumer species was present (Fig. 2b, d; Table 1).

\section{Phytoplankton response after consumer addition (H3)}

The one-factorial ANOVA on the phytoplankton response variables showed no significant differences between the consumer treatments before the consumers were added. However, after the consumer species were added to the phytoplankton cultures, we compensated for random initial differences by measuring the effect of consumer presence and multispecies assemblages on the change in the phytoplankton response variables over the grazing period rather than the absolute values at the end of the experiment.

When considering the change in phytoplankton biomass $\left(\mathrm{C} \mu \mathrm{mol} \mathrm{L} \mathrm{L}^{-1}\right)$ over the grazing period ( $\Delta$ biomass), a significantly negative planned contrast ( 0 vs. 1$)$ under HL $\mathrm{N}+$ revealed that phytoplankton biomass increased less in the consumer treatments compared to the consumer-free control (Fig. 3a; Table 2). When comparing the observed values of phytoplankton $\Delta$ biomass in polycultures with the expected performance based on the monoculture outcome (NDE), the significant negative NDEs on phytoplankton $\Delta$ biomass under $\mathrm{LL}(\mathrm{N}+$ and $\mathrm{N}-$ ) conditions revealed that consumer polycultures reduced phytoplankton biomass more than expected from monocultures (Fig. 3b; Table 3).

Consumer presence ( 0 vs. 1) resulted in significantly lower phytoplankton RUE and NUE during the grazing period (see $\Delta$ values) under HL N+(Fig. 3c, e; Table 2) while NUE significantly increased under LL N- when consumers were present (Fig. 3e; Table 2). When comparing the observed polyculture values with the expected monoculture performance, significantly negative NDE on phytoplankton $\Delta$ RUE under LL ( + and $\mathrm{N}-$ ) indicates that the presence
Fig. 2 Effects of the factorial combination of light and nitrogen availability on the consumer elemental ratios $(\mathbf{a}, \mathbf{c}, \mathbf{e})$ of the different consumer species in monocultures and polycultures (mean $\pm \mathrm{SE})$, as well as the $\operatorname{NDE}(\mathbf{b}, \mathbf{d}, \mathbf{f})$ for the respective response variables. For abbreviations, see Fig. 3
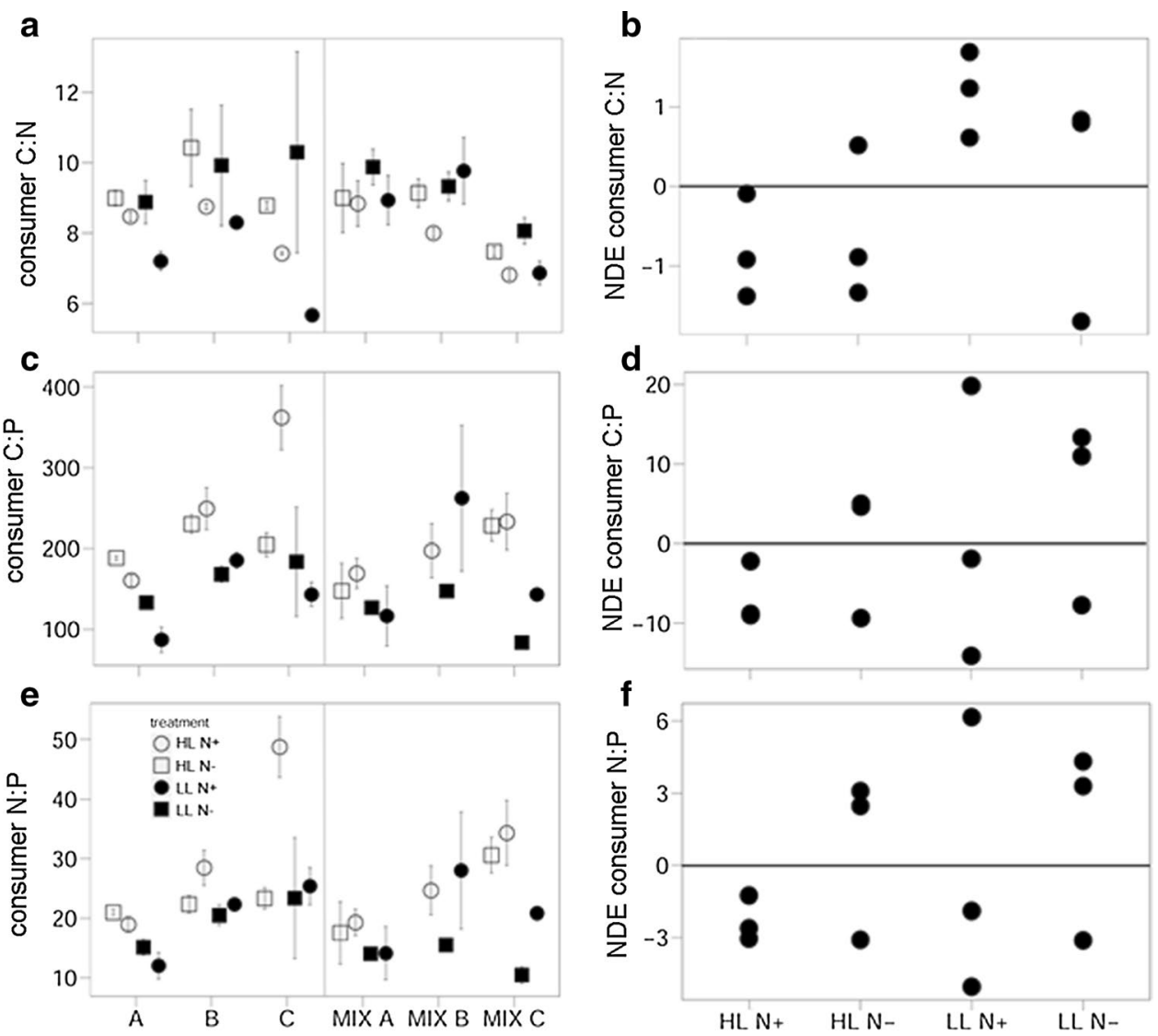
Fig. 3 Left panel shows a phytoplankton (algal) biomass (C $\left.\mu \mathrm{mol} \mathrm{L}{ }^{-1}\right)$, c RUE and e NUE as the change over the grazing period $(\Delta)$ in response to the factorial combination of light and nitrogen availability under different grazing scenarios (mean \pm SE). Right panel shows the NDE (net diversity effect) for $\mathbf{b}$ phytoplankton biomass, d RUE and $\mathbf{f}$ NUE. Values for NDE are square-root transformed. A, Artemia salina; $\mathrm{B}$, Brachionus plicatilis; $\mathrm{C}$, Copepod Acartia tonsa; MIX, consumer polyculture; HL, high light; LL, low light; $\mathrm{N}$, nitrogen enriched; $\mathrm{N}-$, nitrogen limited

Table 2 ANOVA planned contrasts ( 0 vs. 1$)$ for phytoplankton (algal) response variables over the grazing period ( $\Delta$ values)
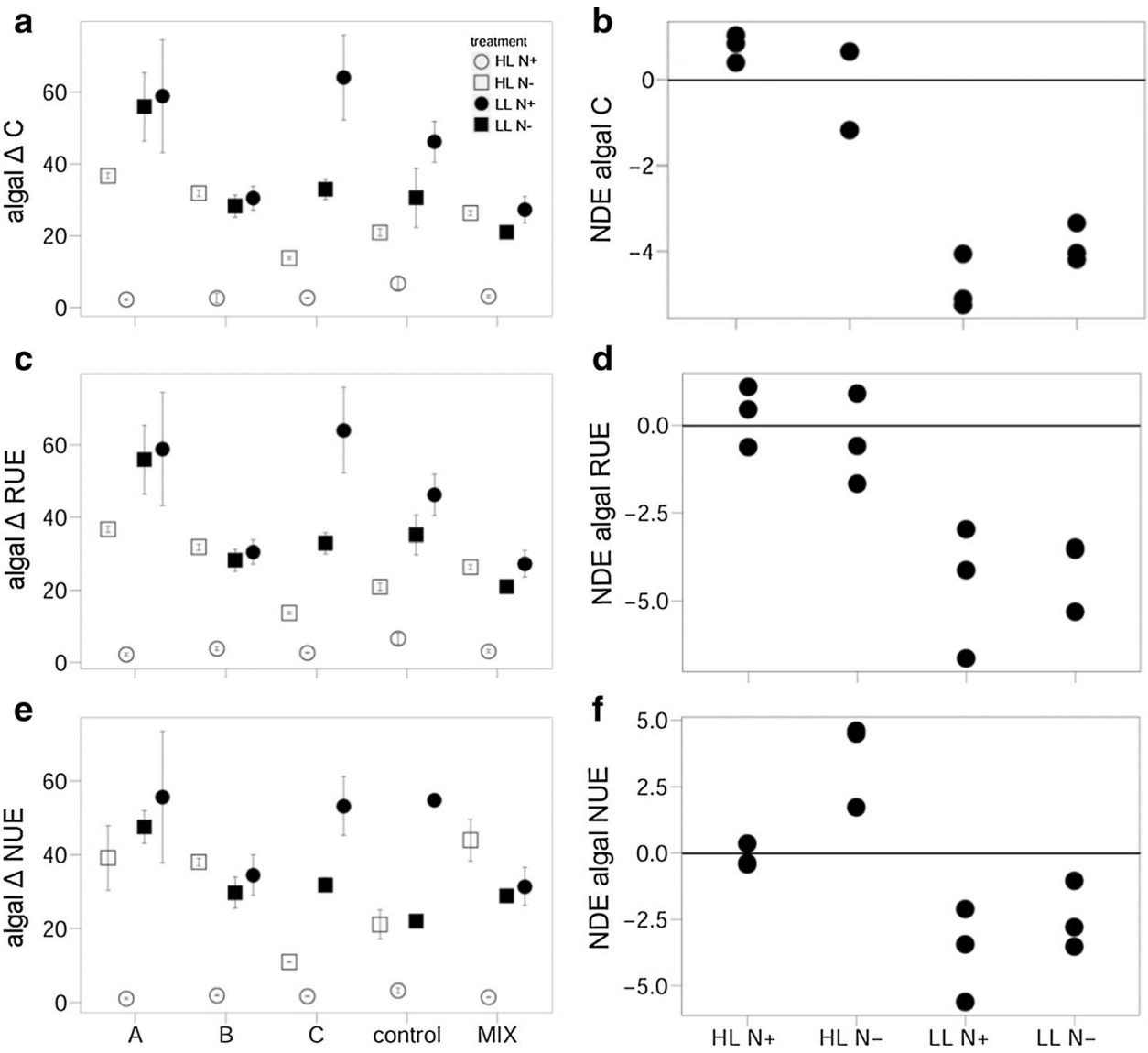

\begin{tabular}{|c|c|c|c|c|c|c|c|c|}
\hline \multirow[t]{2}{*}{ Response } & \multicolumn{2}{|l|}{ HL N+ } & \multicolumn{2}{|l|}{ HL N- } & \multicolumn{2}{|l|}{ LL N+ } & \multicolumn{2}{|l|}{ LL N- } \\
\hline & $F$ & $p$ & $F$ & $p$ & $F$ & $p$ & $F$ & $p$ \\
\hline Algal $\Delta \mathrm{C}$ & 16.981 & $<0.01$ & 1.3575 & 0.2649 & 0.0057 & 0.9408 & 0.1575 & 0.6979 \\
\hline Algal $\Delta$ RUE & 18.233 & $<0.01$ & 1.3575 & 0.2649 & 0.0057 & 0.9408 & 0.0052 & 0.9438 \\
\hline Algal $\Delta$ NUE & 18.589 & $<0.01$ & 1.6098 & 0.2268 & 0.9560 & 0.346 & 5.0166 & $<0.05$ \\
\hline Algal $\Delta \mathrm{C}: \mathrm{N}$ & 0.1136 & 0.7414 & 0.2287 & 0.6404 & 2.2773 & 0.1552 & 17.498 & $<0.01$ \\
\hline Algal $\Delta \mathrm{C}: \mathrm{P}$ & 11.699 & $<0.01$ & 2.9907 & 0.1074 & 1.7151 & 0.213 & 19.743 & $<0.001$ \\
\hline Algal $\Delta \mathrm{N}: \mathrm{P}$ & 14.778 & $<0.05$ & 1.8777 & 0.1938 & 1.108 & 0.3117 & 24.287 & $<0.001$ \\
\hline
\end{tabular}

Significant values of the $t$ test are shown in bold. The first row indicates the factorial combination of light and nitrogen

$H L$ high light, $L L$ low light, $N+$ nitrogen enriched, $N$ - nitrogen limited

Table $3 t$ test results for the NDEs on phytoplankton (algal) response variables over the grazing period ( $\Delta$ values)

\begin{tabular}{|c|c|c|c|c|c|c|c|c|}
\hline \multirow[t]{2}{*}{ Response } & \multicolumn{2}{|l|}{ HL N+ } & \multicolumn{2}{|l|}{ HL N- } & \multicolumn{2}{|l|}{ LL N+ } & \multicolumn{2}{|l|}{ LL N- } \\
\hline & $t$ value & $p$ & $t$ value & $p$ & $t$ value & $p$ & $t$ value & $p$ \\
\hline Algal $\Delta \mathrm{C}$ & 3.998 & 0.057 & -0.928 & 0.451 & -12.814 & $<0.01$ & -14.693 & $<0.01$ \\
\hline Algal $\Delta$ RUE & 0.610 & 0.603 & -0.608 & 0.605 & -4.222 & 0.050 & -6.887 & $<0.05$ \\
\hline Algal $\Delta$ NUE & -0.599 & 0.609 & 3.830 & 0.061 & -3.651 & 0.067 & -3.344 & 0.079 \\
\hline Algal $\Delta \mathrm{C}: \mathrm{N}$ & 0.374 & 0.743 & -3.721 & 0.065 & -2.848 & 0.104 & -4.521 & $<0.05$ \\
\hline Algal $\Delta \mathrm{C}: \mathrm{P}$ & 10.762 & $<0.01$ & 3.549 & 0.071 & -0.935 & 0.448 & -0.264 & 0.816 \\
\hline Algal $\Delta \mathrm{N}: \mathrm{P}$ & 6.649 & $<0.05$ & 2.944 & 0.098 & -0.573 & 0.624 & 4.102 & 0.054 \\
\hline
\end{tabular}

Significant values of the $t$ test are shown in bold, marginal significant values in italic only. For abbreviations, see Table 1 
of multiple consumer species decreased phytoplankton RUE over the grazing period (Fig. 3d; Table 3). Although phytoplankton $\Delta$ NUE showed the same trend as the $\Delta$ RUE, the NDE for $\Delta$ NUE was marginally non-significant (Fig. 3f; Table 3).

Phytoplankton C:N significantly decreased under LL $\mathrm{N}$ - over the grazing period when consumers were present but increased in the consumer-free control. This was mainly based on the relatively strong decrease of phytoplankton C:N when grazed by $B$. plicatilis and the MIX culture, while it stayed constant with $A$. tonsa but increased in A. salina cultures. However, due to the relatively strong increase of phytoplankton $\mathrm{C}: \mathrm{N}$ in the consumer-free control, $\Delta \mathrm{C}: \mathrm{N}$ was significantly lower with consumer presence (planned contrast 0 vs. 1, Fig. 4a; Table 2). Phytoplankton C:N further decreased under LL N- when more than one consumer species was present (Fig. 4b; Table 3), indicated by a significantly negative NDE on phytoplankton $\Delta \mathrm{C}: \mathrm{N}$.

The planned contrast on phytoplankton $\Delta \mathrm{C}: \mathrm{P}$ and $\Delta$ $\mathrm{N}: \mathrm{P}$ between consumer treatments and the consumer-free control (0 vs. 1) showed that both, phytoplankton $\Delta \mathrm{C}: \mathrm{P}$ and $\Delta \mathrm{N}: \mathrm{P}$ were significantly lower under HL $\mathrm{N}+$ when consumers were present, irrespective of consumer identity (Fig. 4c, e; Table 2). This indicates that phytoplankton
$\mathrm{C}: \mathrm{P}$ and $\mathrm{N}: \mathrm{P}$ increased less under grazing pressure or even

Table 4 Phytoplankton response to light, nitrogen and the interaction of both before grazing tested with a two-factorial ANOVA

\begin{tabular}{lllcr}
\hline Response & Factor & $d f$ & $F$ & $p$ \\
\hline Biomass & Light & 1 & 497.67 & $<0.001$ \\
& Nitrogen & 1 & 430.4 & $<0.001$ \\
& Light $\times$ nitrogen & 1 & 434.85 & $<0.001$ \\
RUE & Light & 1 & 3.1108 & 0.087 \\
& Nitrogen & 1 & 67.7372 & $<0.001$ \\
& Light $\times$ nitrogen & 1 & 69.6467 & $<0.001$ \\
NUE & Light & 1 & 3.6414 & 0.066 \\
& Nitrogen & 1 & 47.0745 & $<0.001$ \\
& Light $\times$ nitrogen & 1 & 74.4110 & $<0.001$ \\
C:N & Light & 1 & 114.78 & $<0.001$ \\
& Nitrogen & 1 & 116.48 & $<0.001$ \\
& Light $\times$ nitrogen & 1 & 50.13 & $<0.001$ \\
C:P & Light & 1 & 118.42 & $<0.001$ \\
& Nitrogen & 1 & 114.44 & $<0.001$ \\
& Light $\times$ nitrogen & 1 & 184.67 & $<0.001$ \\
& Light & 1 & 113.23 & $<0.001$ \\
$\mathrm{~N}: \mathrm{P}$ & Nitrogen & 1 & 212.84 & $<0.001$ \\
& Light $\times$ nitrogen & 1 & 276.83 & $<0.001$ \\
\hline
\end{tabular}

Fig. 4 Phytoplankton (algal) elemental ratios $(\mathbf{a}, \mathbf{c}, \mathbf{e})$ as the change over the grazing period (delta) in response to the factorial combination of light and nitrogen availability under different grazing scenarios (mean \pm SE). Right panel (b, d, f) shows the NDE for the respective elemental ratios. For abbreviations see Fig. 1
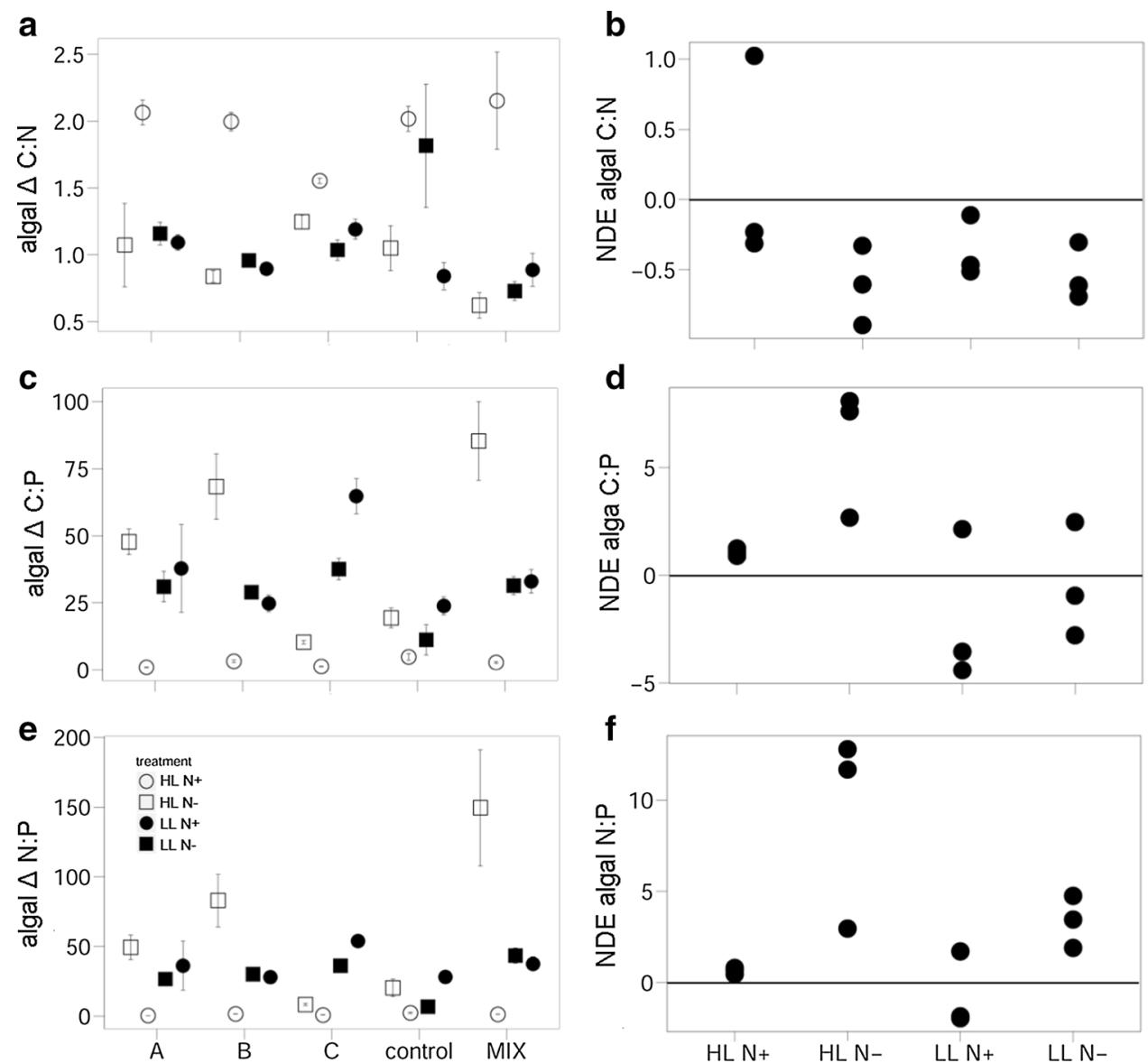
before grazing
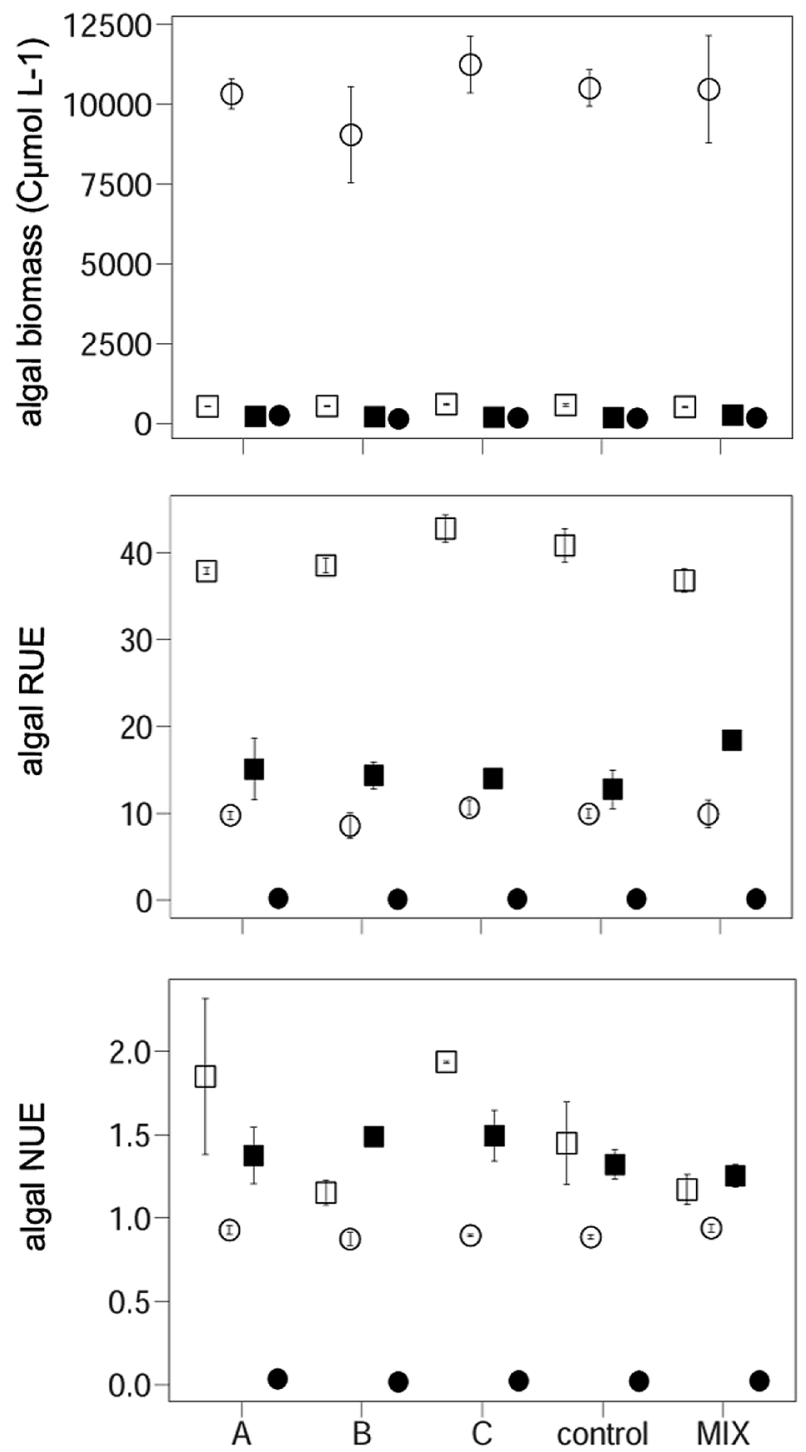

after grazing
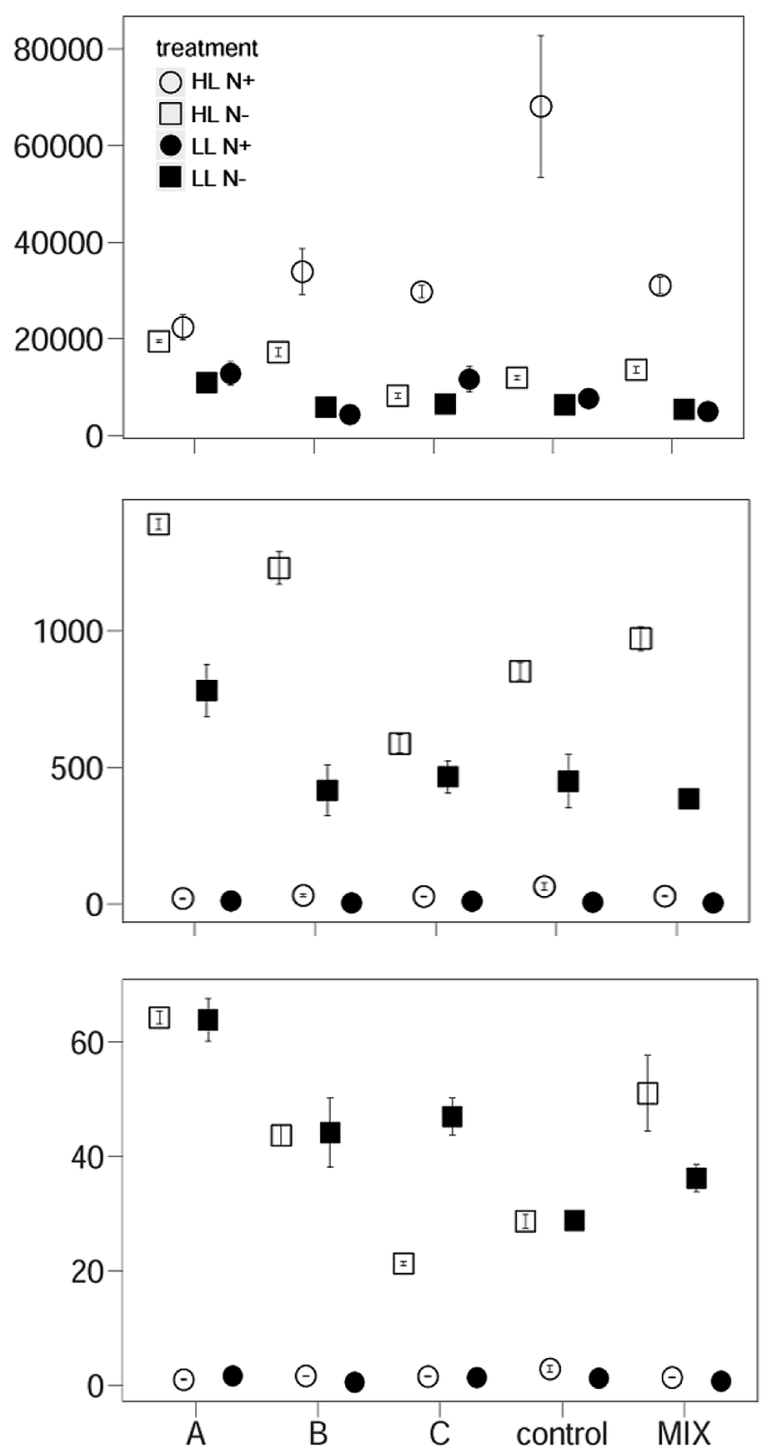

Fig. 5 Algal biomass (algal $\mathrm{C} \mu \mathrm{mol} \mathrm{L}{ }^{-1}$ ), RUE and NUE in response to the factorial combination of light and nitrogen availability (mean \pm SE) before grazing (left panel) and after grazing (right panel). HL, high light; LL, low light; $\mathrm{N}+$, nitrogen enriched; $\mathrm{N}-$, nitrogen limited

decreased compared to the control, as observed for $\mathrm{N}: \mathrm{P}$ in cultures grazed by A. tonsa and A. salina (Fig. 4c, e). Under LL N-, in turn, significantly higher phytoplankton $\Delta \mathrm{C}: \mathrm{P}$ and $\Delta \mathrm{N}: \mathrm{P}$ in the presence of consumers reflect a stronger increase in $\mathrm{C}: \mathrm{P}$ and $\mathrm{N}: \mathrm{P}$ compared to the control treatment (Fig. 4c, e).

When comparing the observed polyculture $\Delta \mathrm{C}: \mathrm{P}$ and $\Delta \mathrm{N}: \mathrm{P}$ ratios with the expected ratios based on the monoculture performance, a significantly positive NDE revealed that $\Delta \mathrm{C}: \mathrm{P}$ and $\Delta \mathrm{N}: \mathrm{P}$ were higher in multispecies assemblages under HL N+(Fig. 4d, f; Table 3). In addition, the same result was observed for phytoplankton $\Delta \mathrm{N}: \mathrm{P}$ under LL N-. This indicates that, under certain resource supply ratios, phytoplankton $\mathrm{C}: \mathrm{P}$ and $\mathrm{N}: \mathrm{P}$ increased strongly over the grazing period when more than one consumer species was present.

\section{Discussion}

\section{Phytoplankton response to resource supply before grazing}

The differences in resource availability and supply ratios significantly altered phytoplankton biomass and stoichiometry in a range that was substantial to allow testing of our main hypothesis. The interaction between light and 

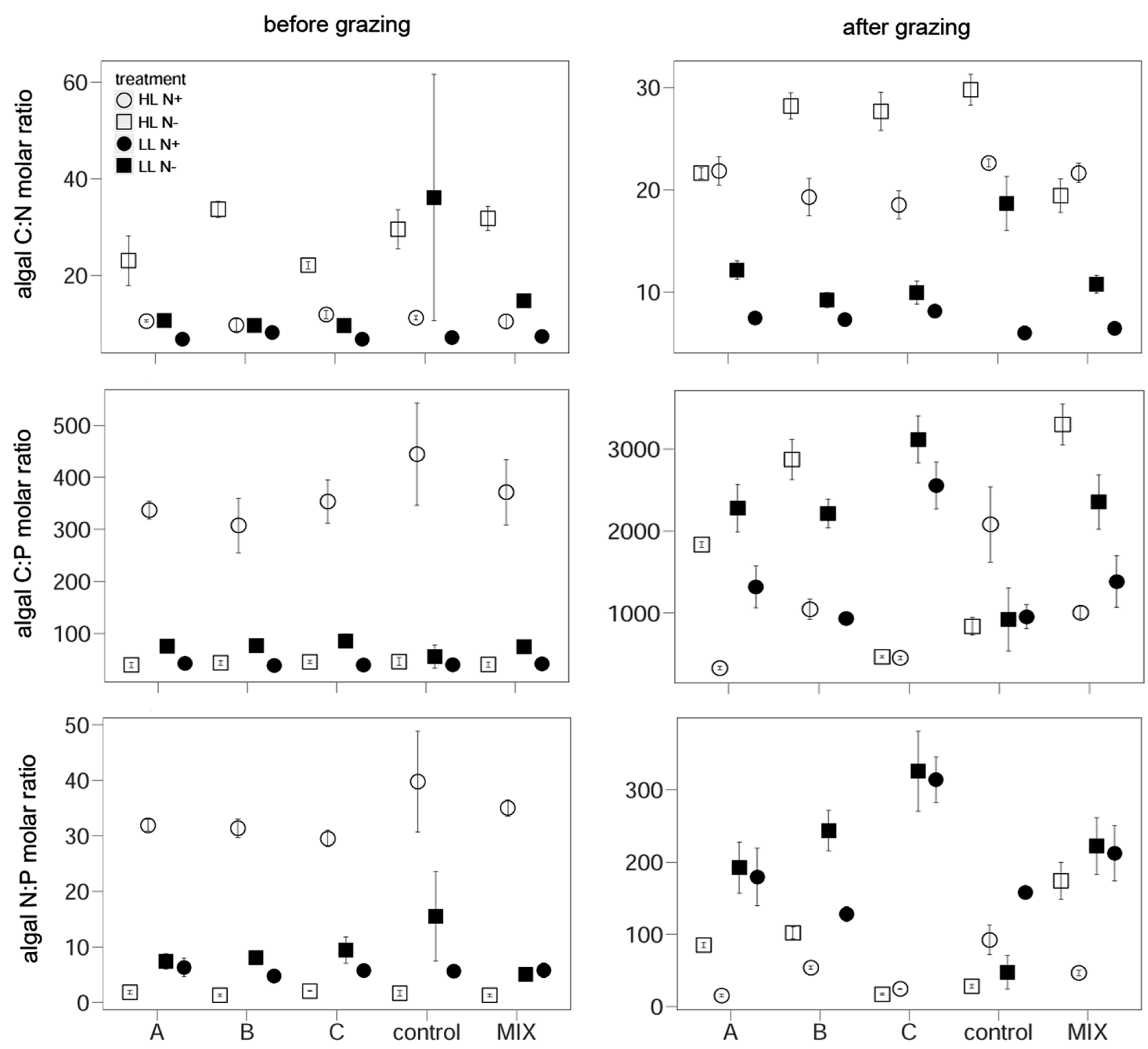

Fig. 6 Algal elemental ratios (molar C:N, C:P and N:P) in response to the factorial combination of light and nitrogen availability (mean \pm SE) before grazing (left panel) and after grazing (right panel). For abbreviations, see "Fig. 5 in Appendix"

$\mathrm{N}$ supply revealed that low-light conditions mitigate the effect of $\mathrm{N}$, as observed in a previous study with a similar setup (Plum et al. 2015). The underlying mechanisms such as enhanced photosynthetic activity and increased carbon assimilation under high-light conditions as well as reduced $\mathrm{N}$ uptake and luxury consumption of phosphate under reduced $\mathrm{N}$ availability have been comprehensively discussed in previous investigations (Droop 1973; Elrifi and Turpin 1985) and corroborate the main predictions of ecological stoichiometry (Sterner et al. 1997; Elser et al. 2002; Sterner and Elser 2002). Therefore, we focus our discussion on the effects of single versus multiple consumer species on consumer and producer performance ( $\mathrm{H} 2$ and $\mathrm{H} 3$ ).

\section{Consumer response to phytoplankton biomass and stoichiometry (H1)}

The observed changes in phytoplankton stoichiometry strongly correlated with consumer biomass and partially with consumer stoichiometry, thereby supporting H1. Highest consumer individual biomass was observed under $\mathrm{HL}$ $\mathrm{N}+$ where we also detected elevated phytoplankton C:P and N:P. Overall, consumer C:N and C:P ratios of all species tend to increase with phytoplankton $\mathrm{C}$ :nutrient ratios, although phytoplankton C:N explained only $37 \%$ of the variance in zooplankton $\mathrm{C}: \mathrm{N}$ and the positive relation between consumer and phytoplankton $\mathrm{C}: \mathrm{P}$ ratios was marginally non-significant. Elevated herbivore $\mathrm{C}$ :nutrient ratios in face of increasing phytoplankton $\mathrm{C}$ :nutrient ratios may seem 


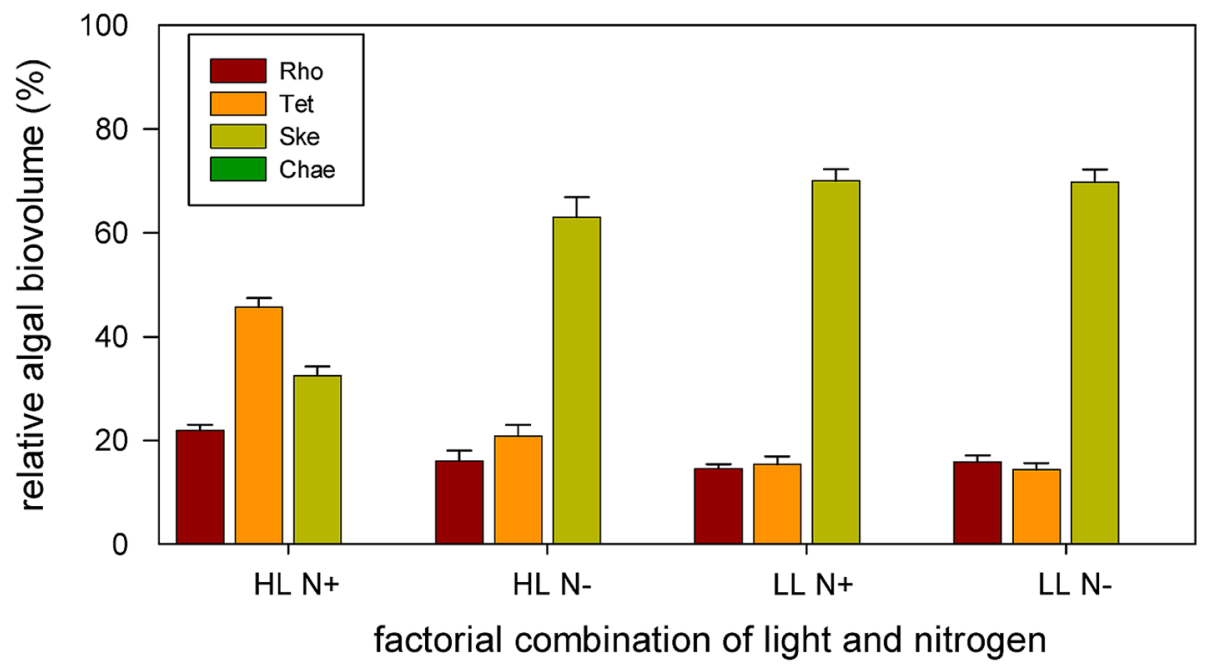

Fig. 7 Skeletonema costatum (Ske) was proportionally the most abundant species in the algal assemblages (except for $\mathrm{HL}+\mathrm{N}$ ) with up to $70 \%$ of the total biovolume. Both, Rhodomonas salina (Rho) and Tetraselmis sp. (Tet) remained below $20 \%$ of total biovolume. The proportions were more equally distributed at $\mathrm{HL}$ and $+\mathrm{N}$ which

contradictory considering consumers' ability of homeostatic regulation. However, despite heterotrophic metazoans' ability to keep their chemical composition in a narrow range compared to their food, homeostatic regulation is not always entirely strict. Thus, varying degrees of homeostasis can result in altered body stoichiometry under increased variability in elemental resource supply ratios (Sterner and Elser 2002; Persson et al. 2010). In fact, correlations between consumer and phytoplankton elemental ratios have been frequently reported in previous studies (Hillebrand and Cardinale 2004; Van Nieuwerburgh et al. 2004; Malzahn et al. 2010). Consequently, our results support the main predictions of the ecological stoichiometry concept and corroborate with previous observations and models (Sterner and Elser 2002; Van de Waal et al. 2018).

\section{Effect of consumer diversity on consumer performance (H2)}

The response of consumer biomass and stoichiometry to the supply ratios of light and $\mathrm{N}$ and the resulting phytoplankton food quality was significantly altered by consumer polycultures, thereby supporting $H 2$. Previous studies on the relation between consumer diversity and biomass production were mainly conducted under homogenous resource supply, demonstrating positive effects of higher consumer richness on the accumulation of biomass (Duffy 2003, 2005; Gamfeldt et al. 2005; Moorthi et al. 2008; Filip et al. 2014). However, it has been shown that the relationship between biodiversity and realized productivity is influenced by the supply and balance of resources (Gross and Cardinale 2007; was mainly based on the dominance of Tetraselmis sp. (up to 50\% of total biovolume) and higher proportions of the subdominant species Rhodomonas salina (up to $25 \%$ of total biovolume). The biovolume of Chaetoceros danicus (Chae) contributed less than $1 \%$ to the total algal biovolume under all resource conditions

Hillebrand and Lehmpfuhl 2011). Although these concepts primarily referred to biomass production of producers, our results provide experimental evidence that this concept can be extended to the consumer level. In other words, the supply of essential as well as substitutable resources such as prey organisms, and the ratio in which they are supplied can alter the effect of consumer assemblages on consumer biomass. In our experiment, consumer biomass significantly increased in the consumer assemblages compared to monoculture performance under elevated resource supply (HL $\mathrm{N}+$ ) but decreased in consumer assemblages under $\mathrm{LL}-\mathrm{N}$.

Although we did not further partition the net diversity effect, we suggest non-transgressive overyielding as the underlying mechanism for the observed increase in consumer biomass under high resource supply. This assumption is supported by the fact that the biomass of the average consumer assemblage was higher than expected but did not exceed the most productive consumer monoculture (Hector et al. 2002). The observed significant increase in consumer resource use efficiency (RUE) and $\mathrm{N}$ uptake efficiency (NUE) with consumer richness further supports this assumption.

In addition, the phytoplankton assemblages used in our experiment increased the probability of containing more edible species, thereby increasing niche dimensionality and consequently reducing the chance that the herbivore assemblages were limited by the same prey. This increased the chance for complementarity in resource use among consumers via niche partitioning. However, the potential surplus in resources provided by phytoplankton assemblages was utilized more efficiently in consumer polycultures under 
high-light conditions only. The non-significant or negative response in consumer polycultures under the other factorial resource combinations indicated that potential positive effects such as resource partitioning or facilitation may have been eliminated by negative effects of interspecific competition (Duffy 2002; Bruno and Cardinale 2008). The lack of a positive diversity-productivity relationship in assemblages of functional equivalent consumers has been reported previously (Fox 2004). This effect cannot be excluded in our study since all consumer species preferentially grazed on $R$. salina and Tetraselmis under low resource supply. The decreased amount of phytoplankton biomass under low-light conditions potentially further enhanced competition among herbivores, thereby limiting consumer's growth via quantitative food limitation. Effects of quantitative limitation would explain lower or constant biomass production in consumer assemblages in face of an increase in resource use efficiency.

Besides the relation between diversity and biomass production, variability in supply of essential resources and prey organisms partly altered the effect of herbivore diversity on consumer elemental ratios, that is, consumer $\mathrm{N}: \mathrm{P}$ ratios decreased in herbivore assemblages under high light and $\mathrm{N}$ enrichment. One potential explanation for the variability in tissue elemental composition of the consumer species is the unequal change in consumer resource use and nutrient uptake. Consumer species assimilated more phosphorus in relation to $\mathrm{N}$ and carbon when grown in mixtures. This was particularly observed in the copepod cultures. The relative and absolute $\mathrm{P}$ content of copepods in the mixed cultures was about two times higher compared to the copepod monoculture under HL N+. These differences in copepod $\mathrm{N}: \mathrm{P}$ between mono- and mix cultures mainly contributed to the lower N:P ratios in consumer assemblages. While the effects of richness on elemental ratios have not been tested on consumer level so far, studies on the phytoplankton diversity-productivity relationship have suggested alteration in resource use efficiency and nutrient uptake as a mechanism for changes in elemental ratios (Striebel et al. 2008; Plum et al. 2015).

\section{Response of phytoplankton to consumer diversity (H3)}

Our experiment showed that consumer diversity significantly altered phytoplankton biomass in a multispecies assemblage, but the magnitude and direction of the effect significantly depended on resource supply ratios, thereby corroborating previous assumptions (Hillebrand and Lehmpfuhl 2011; O'Connor and Donohue 2013).

While consumer assemblages had no effect on phytoplankton biomass under high-light conditions, consumer polycultures reduced phytoplankton biomass more than expected from monoculture performance under depleted light availability. The negative effect of higher consumer richness on phytoplankton biomass accelerated the simple additive effect of higher consumer density. Increased effect sizes of consumer assemblages on producer biomass have been reported previously, suggesting higher resource use in consumer assemblages due to resource partitioning as the underlying mechanism (Gamfeldt et al. 2005; Ives et al. 2005; Bruno et al. 2008; Jaschinski et al. 2009).

In addition to the alteration of producer biomass, the manipulation of consumer species richness affected producer stoichiometry. Overall, phytoplankton resource use efficiency and nutrient uptake increased over the grazing period of our experiment. However, consumer diversity tended to dampen the ability of the phytoplankton community to accumulate more carbon per unit nutrient (lower RUE) or to assimilate more nutrients (lower NUE), indicated by the significant negative NDE on phytoplankton RUE and NUE.

Subsequently, unequal changes in phytoplankton carbon assimilation and nutrient uptake resulted in lower phytoplankton C:N ratios under LL N- but increased phytoplankton $\mathrm{C}: \mathrm{P}$ and $\mathrm{N}: \mathrm{P}$ ratios under $\mathrm{HL} \mathrm{N+}$ when more than one consumer species was present. The observed pattern for phytoplankton $\mathrm{C}: \mathrm{N}$ ratios corroborates previous findings described for periphyton assemblages in rock pool communities (Hillebrand et al. 2009) while a meta-analysis has demonstrated that indirect grazing effects can alter producer C:P and N:P ratios (Hillebrand et al. 2008). Phytoplankton $\mathrm{C}: \mathrm{N}$ ratios in our experiment were either affected by increased $\mathrm{N}$ uptake but constant carbon accumulation under HL N- or reduced carbon content per unit $\mathrm{N}$ under LL N-, that is, consumer richness increased the relative cellular $\mathrm{N}$ content in phytoplankton assemblages. The reduced phosphorus uptake in comparison to carbon accumulation and simultaneously increasing $\mathrm{N}$ uptake was responsible for the lower relative phosphorus content and thus enhanced phytoplankton C:P and N:P ratios under high-light conditions. Although information on excretion is not available, increased $\mathrm{N}$ content in the phytoplankton assemblages indicates that consumer assemblages may have shown enhanced excretion of $\mathrm{N}$. Consumer diversity may have increased $\mathrm{N}$ regeneration via complementarity in resource use indicated by the overall increased NUE in consumer polycultures. Furthermore, the N-limited consumer polycultures showed higher than expected consumption on phytoplankton biomass compared to consumer monocultures (negative NDE on phytoplankton biomass). This pattern corresponds to previous studies, suggesting that decreasing phytoplankton $\mathrm{C}: \mathrm{N}$ ratios may have been a consequence of enhanced $\mathrm{N}$ excretion and more efficient biomass removal by more species rich consumer cultures (Liess and Haglund 2007; Hillebrand et al. 2009).

In conclusion, our observations indicate that acrosslevel diversity effects can alter the transfer of resources between adjacent trophic levels. Consumer assemblages 
can significantly increase the biomass production of the species involved, the efficiency in resource use and nutrient uptake but decrease elemental ratios. Changes in biomass and resource use were mainly driven by niche complementarity within the consumer level while unequal changes of resource use and nutrient uptake were mainly responsible for changes in body stoichiometry. Consumer diversity significantly altered biomass, resource use and elemental ratios of the phytoplankton assemblage via topdown effects, i.e., enhanced consumption in consumer assemblages and potentially increased nutrient regeneration rates. The effects of consumer assemblages strongly depended on the availability of resources and their supply ratio. Our study implies that the influence of resource supply rates and ratios is not only limited to the effect of essential resources on primary producers but also applies to the consumer level. The influence of resource availability on consumer diversity effects increases the complexity of the relationship between biodiversity and ecosystem functions, making it more challenging to define the direction of diversity-related changes in the functional responses within and across trophic levels.

In summary, our study describes for the first time how interactive effects between phytoplankton assemblages and changes in consumer diversity may influence the stoichiometric interactions across adjacent trophic levels with multiple consumer species present. Understanding how multi-trophic changes in species richness affect the energy and resource transfer in pelagic communities is crucial to understand the impact of biodiversity loss and nutrient addition on ecosystem functioning. Moreover, the ongoing alteration of major biogeochemical cycles (Elser et al. 2009; Doney 2010; Elser and Bennet 2011; Peñuelas et al. 2012; Carnicer et al. 2015) highlights the need of bridging biodiversity and biogeochemistry research to understand and predict how human activities are affecting pelagic food webs from regional to global scale (Mace et al. 2012; Cardinale et al. 2012; Welti et al. 2017).

Acknowledgements We thank Heike Rickels for technical support, as well as Mareen Möller and Samuel Nietzer for their support during the experiment. We additionally thank Maren Striebel, Stefanie Moorthi and Thomas Anderson for their competent and fruitful feedback on the manuscript. We also thank two anonymous reviewers for their helpful comments on the manuscript.

Funding This study was funded by the German Research Council (Deutsche Forschungsgemeinschaft DFG Hi 848 7-1).

Data availability The datasets generated during and/or analyzed during the current study are available from the corresponding author on reasonable request.

\section{Compliance with ethical standards}

Conflict of interest The authors declare that they have no conflict of interest.

Ethical approval All applicable international, national, and/or institutional guidelines for the care and use of animals were followed by the authors.

\section{Appendix}

See Table 4, and Figs. 5, 6 and 7.

\section{References}

Boersma M, Aberle N, Hantzsche FM, Schoo KL, Wiltshire KH, Malzahn AM (2008) Nutritional limitation travels up the food chain. Int Rev Hydrobiol 93:479-488. https://doi.org/10.1002/ iroh.200811066

Bruno JF, Cardinale BJ (2008) Cascading effects of predator richness. Front Ecol Environ 6:539-546

Bruno JF, Boyer KE, Duffy JE, Lee SC (2008) Relative and interactive effects of plant and grazer richness in a benthic marine community. Ecology 89:2518-2528

Burson A, Stomp M, Akil L, Brussaard CPD, Huisman J (2016) Unbalanced reduction of nutrient loads has created an offshore gradient from phosphorus to nitrogen limitation in the North Sea. Limnol Oceanogr 61:869-888

Cardinale BJ, Harvey CT, Gross K, Ives AR (2003) Biodiversity and biocontrol: emergent impacts of a multi-enemy assemblage on pest suppression and crop yield in an agroecosystem. Ecol Lett 6:857-865

Cardinale BJ, Hillebrand H, Harpole WS, Gross K, Ptacnik R (2009) Separating the influence of resource 'availability' from resource 'imbalance' on productivity-diversity relationships. Ecol Lett $12: 475-487$

Cardinale BJ, Duffy JE, Gonzalez A, Hooper DU, Perrings C, Venail P, Narwani A, Mace GM, Tilman D, Wardle DA, Kinzig AP, Daily GC, Loreau M, Grace JB, Larigauderie A, Srivastava DS, Naeem S (2012) Biodiversity loss and its impact on humanity. Nature. 486:59-67. https://doi.org/10.1038/nature11148

Carnicer J, Sardans J, Stefanescu Cm Ubach A, Bartrins M, Asensio D, Peñuelas J (2015) Global biodiversity, stoichiometry and ecosystem responses to human-induced C-N-P imbalances. J Plant Physiol 172:82-91

Chen M, Fan M, Kuang Y (2017) Global dynamics in a stoichiometric food chain model with two limiting nutrients. Math Biosci 289:9-19

Doi H, Cherif M, Iwabuchi T, Katano I, Stegen JC, Striebel M (2010) Integrating elements and energy through the metabolic dependencies of gross growth efficiency and the threshold elemental ratio. Oikos 119:752-765

Doney SC (2010) The growing human footprint on coastal and openocean biogeochemistry. Science 328:1512-1516

Droop MR (1973) Some thoughts on nutrient limitation in algae. J Phycol 9:264-272

Duffy JE (2002) Biodiversity and ecosystem function: the consumer connection. Oikos 99:201-219

Duffy JE (2003) Biodiversity loss, trophic skew and ecosystem functioning. Ecol Lett 6:680-687 
Duffy JE, Cardinale BJ, Kristin EF, McIntire PB, Thebault E, Loreau M (2007) The functional role of biodiversity in ecosystems: incorporating trophic complexity. Ecol Lett 10:522-538

Elrifi IR, Turpin DH (1985) Steady state luxury consumption and the concept of optimum nutrient ratios: a study with phosphate and nitrate limited Selenastrum minutum (Chlorophyta). J Phycol 21:592-602

Elser JJ, Bennet E (2011) Phosphorus cycle: a broken biogeochemical cycle. Nature 478:29

Elser JJ, Urabe J (1999) The stoichiometry of consumer-driven nutrient recycling: theory, observations, and consequences. Ecology 80:735-751

Elser JJ, Frost P, Kyle M, Urabe J, Andersen T (2002) Effects of light and nutrients on plankton stoichiometry and biomass in a P-limited lake. Hydrobiology 481:101-112

Elser JJ, Andersen T, Baron JS, Bergström AK, Jansson M, Kyle M, Nydick KR, Steger L, Hessen DO (2009) Shifts in lake N:P stoichiometry and nutrient limitation driven by atmospheric nitrogen deposition. Science 326:835-837

Elser JJ, Loladze I, Peace AL, Kuang Y (2012) Lotka re-loaded: modelling trophic interactions under stoichiometric constraints. Ecol Model 245:3-11

Elser JJ, Kyle M, Learned J, McCrackin ML, Peace AL, Steger L (2016) Life on the stoichiometric knife-edge: effects of high and low food C: $p$ ratio on growth, feeding, and respiration in three Daphnia species. Inland Waters 6:136-146

Filip J, Bauer B, Hillebrand H, Beniermann A, Gaedke U, Moorthi SD (2014) Multitrophic diversity effects depend on consumer specialization and species-specific growth and grazing rates. Oikos 123:912-922. https://doi.org/10.1111/oik.01219

Fox JW (2004) Effects of phytoplankton and herbivore diversity on the partitioning of biomass within and among trophic levels. Ecology 85:549-559

Frost PC, Benstead JP, Cross WF, Hillebrand H, Larson JH, Xenopoulos MA, Yoshida T (2006) Threshold elemental ratios of carbon and phosphorus in aquatic consumers. Ecol Lett 9:774-779. https ://doi.org/10.1111/j.1461-0248.2006.00919.x

Gamfeldt L, Hillebrand H (2011) Effects of total resources, resource ratios, and species richness on phytoplankton productivity and evenness at both metacommunity and local scales. PLoS One 6:e21972

Gamfeldt L, Hillebrand H, Jonsson PR (2005) Species richness changes across two trophic levels simultaneously affect prey and consumer biomass. Ecol Lett 8:696-703

Grasshoff K, Kremling K, Ehrhardt M (1999) Methods of seawater analysis, 3rd completely revised and extended edition. Wiley$\mathrm{VCH}$, Weinheim

Grizzetti B, Bouraoui F, Aloe A (2012) Changes of nitrogen and phosphorus loads to European seas. Glob Change Biol 18:769-782

Gross K, Cardinale BJ (2007) Does species richness drive community production or vice versa? Reconciling historical and contemporary paradigms in competitive communities. Am Nat 170:207-220

Guillard RRL, Ryther JH (1962) Studies of marine planktonic diatoms: i. Cyclotella nana hustedt, and Detonula confervacea (Cleve) gran. Can J Microbiol 8:229-239

Hall SR (2009) Stoichiometrically explicit food webs: feedbacks between resource supply, elemental constraints, and species diversity. Annu Rev Ecol Evol Syst 40:503-528

Hall SR, Leibold MA, Lytle DA, Smith VH (2004) Stoichiometry and planktonic grazer composition over gradients of light, nutrients and predation risk. Ecology 85:2291-2301

Hector A, Bazeley-White E, Loreau M, Otway S, Schmid B (2002) Overyielding in grassland communities: testing the sampling effect hypothesis with replicated biodiversity experiments. Ecol Lett 5:502-511. https://doi.org/10.1046/j.1461-0248.2002.00337 .X
Hessen DO, Elser JJ, Sterner RW, Urabe J (2013) Ecological stoichiometry: an elementary approach using basic principles. Limnol Oceanogr 58:2219-2236

Hillebrand H, Cardinale BJ (2004) Consumer effects decline with prey diversity. Ecol Lett 7:192-201

Hillebrand H, Lehmpfuhl V (2011) Resource stoichiometry and consumers control the biodiversity-productivity relationship in pelagic metacommunities. Am Nat 178:171-181

Hillebrand H, Dürselen CD, Kirschtel D, Pollingher U, Zohary T (1999) Biovolume calculation for pelagic and benthic microalgae. J Phycol 35:403-424

Hillebrand H, Frost P, Liess A (2008) Ecological stoichiometry of indirect grazer effects on periphyton nutrient content. Oecologia 155:619-630

Hillebrand H, Gamfeldt L, Jonsson PR, Matthiessen B (2009) Consumer diversity indirectly changes prey nutrient content. Mar Ecol Prog Ser 380:33-41

Hillebrand H, Cowles JM, Lewandowska A, Van de Waal DB, Plum C (2014) Think ratio! A stoichiometric view on biodiversity-ecosystem functioning research. Basic Appl Ecol 15:465-474

Hood JM, Sterner RW (2014) Carbon and phosphorus linkages in Daphnia growth are determined by growth rate, not species or diet. Funct Ecol 28:1156-1165. https://doi. org/10.1111/1365-2435.12243

Hooper DU, Chapin FS, Ewel JJ, Hector A, Inchausti P, Lavorel S, Lawton JH, Lodge DM, Loreau M, Naeem S, Schmid B, Setälä H, Symstad AJ, Vandermeer J, Wardle DA (2005) Effects of biodiversity on ecosystem functioning: a consensus of current knowledge. Ecol Monogr 75:3-35

Ives AR, Cardinale BJ, Snyder WE (2005) A synthesis of subdisciplines: predator-prey interactions, and biodiversity and ecosystem functioning. Ecol Lett 8:102-116

Jaschinski S, Aberle N, Gohse-Reimann S, Brendelberger H, Wiltshire $\mathrm{KH}$, Sommer U (2009) Grazer diversity effects in an eelgrass-epiphyte-microphytobenthos system. Oecologia 159:607-615

Jolliffe PA (2000) The replacement series. J Ecol 88:371-385. https:// doi.org/10.1046/j.1365-2745.2000.00470.x

Knoll LB, McIntyre PB, Vanni MJ, Flecker AS (2009) Feedbacks of consumer nutrient recycling on producer biomass and stoichiometry: separating direct and indirect effects. Oikos 118:1732-1742. https://doi.org/10.1111/j.1600-0706.2009.17367.x

Kraberg A, Bauman M, Dürselen CD (2010) Coastal Phytoplankton. Photo guide for Northern European Seas. Friedrich Pfeil, München

Liess A, Haglund AL (2007) Periphyton responds differentially to nutrients recycled in dissolved or faecal pellet form by the snail grazer Theodoxus fluviatilis. Freshw Biol 52:1997-2008

Loladze I, Kuang Y, Elser JJ, Fagan WF (2004) Competition and stoichiometry: coexistence of two predators on one prey. Theor Popul Biol 65:1-15

Loreau M, Hector A (2001) Partitioning selection and complementarity in biodiversity experiments. Nature 412:72-76

Mace GM, Norris K, Fitter AH (2012) Biodiversity and ecosystem services: a multilayered relationship. Trends Ecol Evol 27:19-26. https://doi.org/10.1016/j.tree.2011.08.006

Malzahn AM, Boersma M (2012) Effects of poor food quality on copepod growth are dose dependent and non-reversible. Oikos 121:1408-1416

Malzahn AM, Aberle N, Clemmensen C, Boersma M (2007) Nutrient limitation of primary producers affects planktivorous fish condition. Limnol Oceanogr 52:2062-2071

Malzahn AM, Hantzsche F, Schoo KL, Boersma M, Aberle N (2010) Differential effects of nutrient-limited primary production on primary, secondary or tertiary consumers. Oecologia 162:35-48

Meunier CL, Haafke J, Oppermann B, Boersma M, Malzahn AM (2012) Dynamic stoichiometric response to food quality 
fluctuations in the heterotrophic dinoflagellate Oxyrrhis marina. Mar Biol 159:2241-2248. https://doi.org/10.1007/s0022 7-012-2009-3

Moorthi SI, Hillebrand H, Wahl M, Berninger UG (2008) Consumer diversity enhances secondary production by complementarily effects in experimental ciliate assemblages. Estua Coasts 31:152-162

O’Connor NE, Donohue I (2013) Environmental context determines multi-trophic effects of consumer species loss. Glob Change Biol 19:431-440

O’Connor MI, Gonzalez A, Byrnes JEK, Cardinale BJ, Duffy JE, Gamfeldt L, Griffin JN, Hooper D, Hungate BA, Paquette A, Thompson PL, Dee LE, Dolan KL (2017) A general biodiversity-function relationship is mediated by trophic level. Oikos 126:18-31

Peace AL, Zhao Y, Loladze I, Elser JJ, Kuang Y (2013) A stoichiometric producer-grazer model incorporating the effects of excess food-nutrient content on consumer dynamics. Math Biosci 244:107-115

Peñuelas J et al (2012) The human-induced imbalance between C, N and $\mathrm{P}$ in earth's life system. Glob Change Biol 18:3-6

Persson J et al (2010) To be or not to be what you eat: regulation of stoichiometric homeostasis among autotrophs and heterotrophs. Oikos 119:741-751

Plum C, Hüsener M, Hillebrand H (2015) Multiple vs single phytoplankton species alter stoichiometry of trophic interaction with zooplankton. Ecology 96:3075-3089

Ptacnik R et al (2008) Diversity predicts stability and resource use efficiency in natural phytoplankton communities. Proc Nat Acad Sci 105:5134-5138

Sardans J, Rivas-Ubach A, Peñuelas J (2012) The C:N:P stoichiometry of organisms and ecosystems in a changing world: a review and perspectives. Perspect Plant Ecol Evol Syst 14:33-47

Schoo KL, Aberle N, Malzahn AM, Boersma M (2010) Does the nutrient stoichiometry of primary producers affect the secondary consumer Pleurobrachia pileus? Aquat Ecol 44:233-242. https://doi. org/10.1007/s10452-009-9265-4

Sih A, Englund G, Wooster D (1998) Emergent impacts of multiple predators on prey. Trends Ecol Evol 13:350-355. https://doi. org/10.1016/S0169-5347(98)01437-2
Snaydon R (1991) Replacement or additive designs for competition studies? J Appl Ecol 28:930-946

Sterner RW (1990) The ratio of nitrogen to phosphorus resupplied by herbivores: zooplankton and the algal competitive arena. Am Nat 136:209-229

Sterner R, Elser J (2002) Ecological stoichiometry. Princeton University Press, Princeton, New Jersey, USA, The biology of elements from molecules to the biosphere

Sterner RW et al (1997) The light:nutrient ratio in lakes: The balance of energy and materials affects ecosystem structure and process. Am Nat 150:663-684

Striebel M, Spörl G, Stibor H (2008) Light-induced changes of plankton growth and stoichiometry: experiments with natural phytoplankton communities. Limnol Oceanogr 53:513-522

Van de Waal DB, Elser JJ, Martiny AC, Sterner RW, Cotner JB (2018) Progress in ecological stoichiometry. Front Microbiol. https://doi. org/10.3389/fmicb.2018.01957

Van Nieuwerburgh L et al (2004) Growth and C:N: P ratios in copepods grazing on $\mathrm{N}$ - or Si-limited phytoplankton blooms. Hydrobiol 514:57-72

Vitousek PM et al (2010) Terrestrial phosphorus limitation: mechanisms, implications, and nitrogen-phosphorus interactions. Ecol Appl 20:5-15

Welti N, Striebel M, Ulseth AJ, Cross WF, DeVilbiss S, Glibert PM, Guo L, Hirst AG, Hood J, Kominoski JS, MacNeill KL, Mehring AS, Welter JR, Hillebrand H (2017) Bridging food webs, ecosystem metabolism, and biogeochemistry using ecological stoichiometry theory. Front Microbiol 8:1298. https://doi.org/10.3389/ fmicb.2017.01298

Publisher's Note Springer Nature remains neutral with regard to jurisdictional claims in published maps and institutional affiliations. 